\title{
Epidemiology of viral hepatitis in men who have sex with men in Mediterranean Europe: a region-wide sero-surveillance in Rome (Italy)
}

Simone Lanini ( $\nabla$ simone.lanini@inmi.it)

INMI Lazzaro Spallanzani IRCCS https://orcid.org/0000-0002-6743-4001

Silvia Meschi

INMI Lazzaro Spallanzani IRCCS

Laura Scorzolini

INMI Lazzaro Spallanzani IRCCS

Giovanna Adamo

INMI Lazzaro Spallanzani IRCCS

Alessandro Agresta

INMI Lazzaro Spallanzani IRCCS

Fabrizio Marrazzo

Gay Center/ Gay Help Line - Rome

Francesco Angeli

Arcigay - Rome

Massimo Farinella

Circolo di cultura omosessuale "Mario Mieli" - Rome

Carlo Guarino

Regione Lazio

Alessandra Barca

Regione Lazio

Lorella Lombardozzi

Regione Lazio

Adriano Possi

INMI Lazzaro Spallanzani IRCCS

Mirko Manganiello

LAZIOcrea - Rome

\section{Patrizia Magrini}

INMI Lazzaro Spallanzani IRCCS

\section{Paola Scognamiglio}

INMI Lazzaro Spallanzani IRCCS

Vincenzo Puro

INMI Lazzaro Spallanzani IRCCS 


\section{Emanuele Nicastri}

INMI Lazzaro Spallanzani IRCCS

\section{Maria Capobianchi}

INMI Lazzaro Spallanzani IRCCS

\section{Alimuddin Zumla}

University College London Division of Infection and Immunity

\section{Giuseppe Ippolito}

INMI Lazzaro Spallanzani IRCCS

\section{Research article}

Keywords: Hepatitis, Viral, Human, HAV, HBV, HCV, Men Who Have Sex With Men, Serosurveillance

Posted Date: May 29th, 2020

DOI: https://doi.org/10.21203/rs.2.22953/v2

License: () (i) This work is licensed under a Creative Commons Attribution 4.0 International License. Read Full License 


\section{Abstract}

OBJECTIVE To describe epidemiology of viral hepatitis (including HAV, HBV and HCV) among men who have sex with men (MSM) aged between 18 and 45 years and living in Lazio, an Italian Region with about 5.9 million inhabitants whose main city is Rome.

METHODS A sero-survey (cross-sectional study) was conducted as part of a screening and prevention campaign for improving control of viral hepatitis in Lazio. The study enrolled 1,100 MSM people participating to the campaign. Outcome measures were serology for HAV (anti-HAV IgG and anti-HAV IgM), serology for HBV (anti-HBs, anti-HBc and HBsAg), and serology for HCV (anti-HCV). Participants' epidemiological features were assessed for potential association with outcomes.

RESULTS We found a very low prevalence of immunity against HAV and a significant exposure to high-risk behaviours, suggesting that gay community of Lazio is an ideal setting for HAV outbreaks. Prevalence of different serology profiles for HBV suggests that waning immunity and escape to mandatory vaccination still represent a significant issue in patients older than 35 years. Moreover, waning immunity suggests that patients who were vaccinated at birth may show low antibody levels. Consistently with other studies, prevalence of HCV infection was very low among young MSM.

CONCLUSION Tailored vaccine programme aimed at immunizing MSM are critical to improve control of $\mathrm{HAV}$ in our setting. Findings on HBV epidemiology suggest that there is a need to define a clear strategy to recover patients who escaped vaccination and inform clinicians on the need to booster subjects with low immunity and high risk of exposure, such as MSM. Finally, MSM in Lazio do not represent a special group for HCV neither in terms of risk of infection nor in terms of potential issues for therapy access.

\section{Background}

Viral hepatitis is a major public health problem affecting millions of people worldwide and is associated with significant morbidity and mortality. Three hepatotropic viruses cause most of the global burden of viral hepatitis: hepatitis A virus (HAV), hepatitis B virus (HBV) and hepatitis $\mathrm{C}$ virus (HCV). HAV is mainly transmitted thought oro-fecal route. There is no therapy against acute hepatitis A. However, vaccine can safely and effectively prevents infection with HAV. HBV is generally transmitted by sexual contacts, through blood and perinatally form mother to her baby. HBV infection may persist lifelong and evolve towards severe conditions including liver cancer and liver cirrhosis. Infection with HBV can be safely and effectively prevent by vaccination. $\mathrm{HCV}$ is mainly a blood borne pathogen. $\mathrm{HCV}$ is associated with chronic infection that may significantly affect life quality and expectancy. There is no vaccine against $\mathrm{HCV}$, nevertheless there are currently available a new drugs that may suppress viral replication and provide a complete clearance of the infection. [1]

The new opportunities for prevention and therapy, made it possible to implement new ambitious programmes for achieving a complete control of viral hepatitis at global. The WHO calls for elimination of viral hepatitis as a public health threat by $2030 .\left[^{2}{ }^{3}\right]$ In low endemic settings, impact of interventions to 
control viral hepatitis can be maximized by targeting special groups at risk that serve as the ultimate human reservoir of these infections. [4-5]

Sexual intercourse between men have been associated with an increased risk of transmission of hepatotropic viruses. HAV is an emerging issue among men-who-have-sex-with-men (MSM) living in industrial countries $\left[^{6}\right]$ while the prevalence of chronic infection with $\mathrm{HBV}\left[{ }^{7}-{ }_{-}{ }^{9}\right]$ and $\mathrm{HCV}\left[{ }^{10}\right]$ is higher in MSM than in general population in many countries.

Between August 2016 and December 2017, a vast epidemic of HAV struck Lazio, a Region in central Italy whose main city is Rome. This event was associated with the spreading of few selected HAV molecular variants that were already found to be the cause of concomitant outbreaks affecting MSM communities other European countries. [6- $\left.{ }^{11}\right]$ In Lazio, the epidemic was particularly intense causing 1013 cases in 16 months with a male to female ratio of about 8.3. Since February 2017 the Regional Health Authority of Lazio has implemented a special vaccine campaign to stop the epidemic. $\left[{ }^{12}\right]$ According to recommendations of the World Health Organization, anti-HAV vaccine was offered within a comprehensive plan for prevention, control and care of other viral hepatitis including HAV, HBV and HCV. [ $\left.{ }^{13 \_}{ }^{14}\right]$ Here we present the results of the sero-surveillance study carried out as a component of the campaign. The results of this study might be useful to better address MSM people in the current programme against viral hepatitis in Italy and other similar setting in Europe.

\section{Methods}

\section{Study design}

The study is a sero-survey carried out by the Italian National Institute for Infectious Diseases Lazzaro Spallanzani (INMI-Spallanzani) as part of a Regional programme "Prevention of viral hepatitis" (Prevenzione delle epatititi virali; PrEV).[12] The report is written according to the STROBE statement guidelines for cross-sectional studies.[15]

\section{Setting}

Lazio is an Italian Region with about 5.9 million inhabitants (of them 2,038,292 are aged 18-45 years). About $47 \%$ of Lazio inhabitants live in Rome, the only large city. All other people live in the 347 municipalities, mainly towns (median habitants: 2674; inter-quartile range [IQR]: 1120-7997).

PrEV is a currently ongoing programme for prevention of viral hepatitis started on February 2017.[12] This programme aims at the adult population aged between 18 and 45 years living in Lazio with special attention towards MSM. In brief, all eligible subjects had access to a free screening for HAV, HBV and HCV and free vaccination for HAV and HBV. Moreover, people were also offered voluntary testing for HIV. All people with evidence of chronic infection with HBV, HCV or HIV were immediately referred to the outpatient's 
clinic of INMI-Spallanzani if not already in care at another clinical centre. Supplementary file 1 report the PrEV screening and intervention flow-chart.

\section{Participants}

This study enrolled all individuals who participated in the vaccine campaign providing that they: A) were male; $B$ ) reported sexual intercourse with males throughout life; C) underwent full screening for HAV, HBV and HCV.

\section{Definitions}

Outcome definition for HAV infection:

- Immune to HAV infection: subjects with detectable anti-HAV IgG and/or anti-HAV IgM;

- Susceptible to HAV infection: subjects with undetectable anti-HAV IgG and anti-HAV IgM antibodies;

Outcome definition for HBV infection.

- Subject who experienced a natural infection with HBV: subjects with detectable antibodies to HBV core antigen (anti-HBc).

- High immunity vaccinated (HI-vaccinated): subjects with antibodies to HBV surface antigen (anti-HBs) $>10 \mathrm{UI} / \mathrm{mL}$ and undetectable anti-HBc;

- Low immunity vaccinated (LI-vaccinated): subjects with anti-HBs between 1 and $10 \mathrm{UI} / \mathrm{mL}$ and undetectable anti-HBc;

- HBV naïve: subjects with undetectable anti-HBs and anti-HBc.

The selection of anti-HBc-Ab as the marker for natural infection is according the last EASL guidelines. [ $\left.{ }^{16}\right]$ The cut off anti-HBsAb titre either below or above $10 \mathrm{U} / \mathrm{L}$ to distinguish between HI-vaccinated and LIvaccinated has been decided according to current international consensus. [17_18]

Outcome definition for HCV

- Subject who experienced a natural infection with HCV: subjects with detectable anti-HCV-Ab;

- HCV naïve: subjects with undetectable anti-HCV-Ab .

\section{Laboratory testing}

At the Laboratory of Virology of the INMI-Spallanzani anti-HAV IgG and IgM, anti-HBc, anti-HBs, HBs Ag and anti-HCV levels were determined in serum samples by the ARCHITECT chemiluminescent microparticle immunoassays on the Architect i2000SR immunoanalyser (Abbott Diagnostics, Wiesbaden, Germany). Serum samples showing low positive signal in Abbott anti-HCV assay $(1 \leq \mathrm{S} / \mathrm{CO}<5)$ were tested by the 
LIAISON® XL murex HCV Ab indirect chemiluminescence assay on the Liaison XL analyser (DiaSorin S.p.A., Saluggia VC, Italy) and considered negative for anti-HCV when S/Co was $<1$. Furthermore, plasma HCV-RNA was quantified using a commercial assay (RealTimeTM HCV; Abbott Molecular Inc., Des Plaines, IL, USA) with a low limit of detection/quantitation (LOD/LLOQ) of $12 \mathrm{IU} / \mathrm{mL}$.

According with current EASL guidelines, we used anti-HBc-Ab as the marker of natural infection with HBV. [16] In particular, when anti-HBc-Ab is present along Anti-HBs-Ab the HBV infection is considered inactive. In contrast, when anti-HBc-Ab is present with undetectable anti-HBs-Ab the HBV infection is considered active. As HBsAg is never detectable when anti-HBsAb are present, the determination of HBsAg was carried out only in samples with detectable anti-HBc and undetectable anti-HBs. HCV RNA was carried out only in samples with detectable anti-HCV-ab.

\section{Data source and ethical statement}

Doctors collected participants' epidemiological information the day the patients received the result of the tests. All data were collected in an ad hoc electronic database approved by INMI Spallanzani ethical board (ethical clearance N.1 of January $24^{\text {th }}$ 2017). Patients were required to sign an informed consent.

\section{Statistical methods}

A set of 18 demographic and behavioural variables were assessed for potential association with outcomes. All these variables were analysed as binary or categorical as reported in table 1.

The association between demographic variables and outcomes was assessed in separate multivariable regression models. Association between demographic variables and HAV sero-status (as a binary outcome) was assessed by a logistic regression model and odds-ratios (OR) were used as the measure of association. A multinomial logistic regression model was used to assess association between demographic variables and HBV sero-status (as polytomous outcome) and relative risk ratios (RRR) were used as the measure of association.

Selection of co-variates (i.e. demographic and behavioural variables) for multivariable models was carried out by a manual backward stepwise approach already described elsewhere. $\left[{ }^{19}\right]$ Briefly, all variables with Pvalue of less than 0.250 at bivariable analysis were included in a first multivariable model that was eventually refined by eliminating variables with P-value more than 0.100 . Likelihood ratio test was used for calculating P-values in the subsequent nested models. Age and HIV status were included as a priori variables in all models. Missing data were handled with a list-wise deletion approach and only subjects with complete information for all demographic and behavioural variables were included in the final analysis. Adjusted marginal effect estimates of probability with relative $95 \% \mathrm{Cl}$ were used for plotting graphs. The STATA V.15.1 statistical package was used for all analyses.

\section{Results}




\section{Participant characteristics}

Between February 2017 and June 2019, one-thousand-eight-hundred subjects were enrolled in the vaccine campaign, of them 1100 were eligible for the study. Three-hundred-ninety-three subjects were excluded because they were not MSM, 306 were excluded because they were female and one was excluded because HAV, HBV and HCV serum specimens were not available. (Figure 1)

Table 1 reports main characteristics of the study sample. Participants' age ranged from 18 to 45 years, with a median age of 33 years (IQR: 27-38). Of them $92.82 \%$ were born in Italy, $84.00 \%$ lived in Rome, $61.09 \%$ had a university education, $14.00 \%$ were student, $10.91 \%$ were unemployed and $74.91 \%$ were workers. Only a sheer minority of participants (1.00\%) used intravenous drugs, a small proportion (14.18\%) used inhaled drugs, little less than a quarter used poppers $(23.55 \%)$ and about half of participants used cannabinoids (49.36\%) at least once in life.

A minority of participants reported to be engaged with steady sexual partner (36.73\%). With regard to the number of sexual partners in the last year, the $58.64 \%$ reported to have had five or less, the $20.00 \%$ between 6 and 12 and the $20.36 \%$ reported 13 or more. The $8.45 \%$ reported to never use condom, the $11.55 \%$ used condom seldom for anal sex (depending on his opinion upon the partner or the situation), the $46.36 \%$ used condom always for anal intercourse and the $33.09 \%$ used condom always for any sexual intercourse. The $61.55 \%$ of participants were aware of post-exposure prophylaxis (PEP), with $9.82 \%$ reporting to have taken PEP at least once in their lives. A similar proportion (61.72\%) was aware of pre-exposure prophylaxis (PREP) with only $1.45 \%$ reporting to have used it. Approximately $2 / 3$ reported to frequent gay bars $(67.92 \%)$; remarkably, $62.18 \%$ reported never having talked with the general practitioner about their sexual behaviours.

Two-hundred-thirty-three participants (21.18\%) reported to be diagnosed with one or more sexual transmitted infections (STI) during the last year for a total of 273 new diagnosis of STI. Of these 99 (36.26 \%) were syphilis, 51 (18.68\%) gonorrhoea, 37 (13.55\%) urethritis, 49 (17.95\%) genital warts, 13 (5.76\%) genital herpes, 7 (2.56\%) pediculosis, $5(1.83 \%)$ chlamydia infections, $3(1.10 \%)$ candidiasis, 2 (0.73\%) acute HIV infection and $7(2.56 \%)$ genito-urinary infection with no microbiological diagnosis. A total of 122 subjects $(11.09 \%)$ were aware of being infected with HIV.

Supplementary file 2 reports prevalence of the above epidemiological features according to patients' serostatus for viral hepatitis.

\section{Predictors of HAV sero-status}

The analysis of predictor has been carried out on 1,074 patients (Figure 1). One-hundred-ninety-six (17.82\%) participants were anti-HAV IgG positive (immune subjects), of them 13 were also positive to anti-HAV IgM suggesting a recent infections.

The final multivariable logistic regression model for HAV (Table 2) included eight exposure variables. Supplementary file 3 reports the stepwise process for selecting variables for the final multivariable model. 
This model provided strong evidence that: being born outside Italy (OR 4.29; $P<0.001)$; the use of cannabinoids ( $\mathrm{OR} 0.64 ; \mathrm{P}=0.014$ ); the use of poppers (1.52; $\mathrm{P}=0.019)$; having a high number of sexual partners (OR 1.78 and OR 1.48; $P=0.015)$ and the HIV infection (OR 0.30; $P=0.001)$ were all significantly associated with positive anti-HAV serology. The analysis provided weak evidence for the association between HAV status and occupation $(P=0.054)$ and communication of sexual behaviours to GP $(0.073)$. In contrast no evidence was found for the association between HAV sero-status and age (Figure 2; $p=0.207$ ).

\section{Predictors of HBV sero-status}

The aim of this analysis is to describe the population according to four mutually exclusive classes of exposure to HBV, i.e. HBV naïve, LI-vaccinated, HI-vaccinated and those who experienced a natural infection with HBV.

Two-hundred-ten (19.09\%) patients were HBV naïve, 173 (15.73\%) were LI-vaccinated, 651 (59.18\%) were HIvaccinated and $66(6.00 \%)$ were naturally exposed. Among the naturally exposed subjects, only 5 had undetectable level of anti-HBs-Ab and one was HBsAg positive, suggesting an active HBV infection. Multivariable model included seven exposure variables and reports adjusted predictions of participants' HBV sero-status as the relative probability of participants for being either LI-vaccinated, HI-vaccinated or naturally exposed instead of being HBV naïve (relative risk ratio; RRR in Table 3). Supplementary file 4 reports the stepwise process for selecting variables for the final multivariable model.

Age acted as the strongest determinant of HBV sero-status. The probability of having received vaccination significantly drops with age, indeed the oldest age group (41-45 years old) is twenty times less likely than the youngest age class (18-25 years old) of being vaccinated either as LI-vaccinated ( $R R R=0.05 ; P<0.001)$ or $\mathrm{HI}$-vaccinated (RRR $=0.05 ; \mathrm{P}<0.001)$. Figure 3 reports estimated effect of age on the probability to show a specific HBV sero-status. Adjusted probabilities suggested that the proportion of patients with optimal vaccine protection against HBV (HI-vaccinated) reached its maximum in people aged 31-35 years and eventually decreases in older age classes. Indeed, a concomitant increase in the proportion of naïve and naturally infected subjects can be noticed in these same age classes.

The place of birth was also strongly associated with HBV sero-status. In fact, patients who were born outside Italy have a lower probability of being vaccinated than those who were born in Italy (RRR 0.35 and $\mathrm{P}=0.012$ for being LI-vaccinated; RRR 0.30 and $\mathrm{P}<0.001$ for being HI-vaccinated). Education level was associated with a higher probability of being $\mathrm{HI}$-vaccinated (RRR $1.60 \mathrm{P}=0.016)$ and with a lower risk of having experienced a natural infection with HBV (RRR 0.51; $P=0.032)$. There was a trend towards an increased familiarity with PREP and the probability of being vaccinated. Indeed, of the 16 patients who reported to have used PREP at least once in life 13 where HI-vaccinated, two experienced a natural infection and 1 was naive. Finally, we found a strong association between natural infection with HBV and use of poppers (RRR 3.06; $\mathrm{P}<0.001$ ). Remarkably, the model suggested that there was no association between HBV sero-status and HIV infection. 


\section{Analysis of serology for HCV}

The prevalence of anti-HCV-Ab was very low, only nine patients had detectable level of antibody in serum $(0.82 \%)$. Of them, all were already aware of their sero-status for HCV. Five had undetectable HCV RNA while four did not come to have additional testing for HCV RNA because declared to be in treatment for HCV in other clinical centres. Due to the very low number of HCV positive subjects, we did not carry out a formal risk analysis. Supplementary file 2 reports distribution of HCV cases according to risk factors.

\section{Discussion}

Here we reported the results of one of the largest studies aimed to describe the epidemiology of viral hepatitis among MSM living in a Mediterranean Europe.

Descriptive analysis suggested that MSM may actually represent a group of people with special epidemiological features. Remarkably, study participants were highly educated (61.09\% graduated), mainly urbanized (84.00\% lived in the only large urban area of Lazio, Rome), had a significant risk for STI (21.18\% cumulative annual risk of any STI) and HIV infection (11.09\% prevalence of HIV infection). The use of condom was generally sub-optimal so that only one-third of subjects used always condom despite that more than $40 \%$ of participants reported six or more different sexual partners per year. The distribution of STI according to the aetiology was very similar to that reported for MSM in other European countries with syphilis $\left[{ }^{20}\right]$ and gonorrhoea $\left.{ }^{21}\right]$ as the most common STI. About $40 \%$ of the sample was unaware of pharmacological prophylaxis against HIV (either PEP or PREP). Use of non-injection recreational drugs was generally higher than that estimated for the Italian male population. [ $\left.{ }^{22}\right]$

The analysis for HAV sero-status suggested that MSM living in Lazio are largely susceptible to hepatitis A (HAV immunity $17.82 \%$ ). Participants who were born outside Italy were more likely to be immune than Italian born ones. This observation was expected, as most of participants born outside Italy were migrants from HAV endemic areas. In contrast, we found that HIV infected participants were three times less likely than HIV uninfected participants of being immune. The reasons for this association may be composite. In fact, recent studies suggested that persons living with HIV infection might fail in developing immunity after vaccination or, even, they might experience an accelerated antibodies waning. [23] Nevertheless, it cannot be excluded that a large proportion of susceptible participants had never received vaccine despite that Italian guidelines recommend that MSM, and in particular those living with HIV, should be immunized. [24_25] A positive association was found between immunity against HAV and either the numbers of sexual partners or the use of poppers, suggesting that these risk factors may be associated with behaviours facilitating HAV transmission (e.g. anal sex games for poppers and promiscuity associated with the number of partners). [26_27] Finally, we found no association between age and HAV sero-status confirming that Lazio is a setting with very low endemic circulation of HAV. [6,11] Overall, this analysis suggested that MSM community in Lazio represents an ideal setting for periodical outbreaks of HAV due to the very low level of immunity and the potential exposure to high-risk behaviours. Recent experiences provided evidence that large and transnational epidemics of HAV are becoming very frequent in industrial countries among MSM. 
$[6,28,29,30,31,32,33,34]$ Active immunization of MSM in low endemic areas, such as European countries, is a critical step toward an optimal control of HAV. Mathematical model suggested that major epidemic can be adverted by vaccinating $50 \%$ of population at risk. [11]

Our study found that age was the strongest predictor of HBV sero-status. The observed variation of HBVsero-status according to age classes was consistent with Italian vaccine policies and underlined potential critical public health aspects. Italy was one of the first countries in the world to implement a vaccination policy, starting in 1983 with a programme targeted to special groups at increased risk. In 1991, immunization became mandatory for all infants, 12-year-old children and people belonging to high-risk groups.[35] Our study suggested that a significant proportion of participants aged $36-40(27.07 \%)$ and aged $41-45(46.03 \%)$ had no detectable immunity against HBV. The potential reasons for this observation can be due to either escape to mandatory vaccination [35] or waning immunity. [ ${ }^{36}$ ] Escape to mandatory vaccination of people belonging to high-risk groups targeted by vaccine campaigns was already reported. $\left[35,{ }^{37}\right]$. Noteworthy, in our population the prevalence of natural infection was about $7.42 \%$ and $19.05 \%$ in the 36-40 and 41-45 age classes respectively, suggesting that the actual cumulative risk of HBV infection among unvaccinated MSM is not negligible, yet.

Another remarkable finding was the significant waning anti-HBs-Ab immunity in all vaccinated participants. Anti-HBs-Ab wane over time following hepatitis B immunisation. [36] The rapidity of the waning is very variable both at individual and population levels. A sero-epidemiological study carried out among Nunavut people (Artic Canada) showed that the level of anti-HBs-Ab may rapidly decrease in infant vaccinal cohorts so that less than $10 \%$ of people aged $5-18$ years had protective level of anti-HBs levels. [ $\left.{ }^{38}\right]$ Other studies demonstrated that a HBV infection could occur in a number of subjects despite that they had received three or more doses of anti-HBV vaccine (breakthrough infection). [39_40_41_42_43_44] Previous studies suggested that breakthrough infections were mainly associated to a weak primary response. [ $\left.{ }^{45}\right]$ However, most recently, breakthrough infections were reported also among people with strong primary response. $\left[{ }^{46}\right]$ The uncertainty regarding the duration of protection of hepatitis $B$ vaccination, especially beyond 30 years after the primary vaccination, needs further studies. $\left[{ }^{47}\right]$ At present experts suggest that a booster vaccination may be useful to reduce the risk of breakthrough infection for persons living in high endemic settings. $[48,49,50]$ In low endemic settings decisions are taken on case-by-case basis.

Other exposures significantly associated to HBV sero-status were: place of birth, education, familiarity with PREP and use of poppers. Participants born outside Italy were about three time less likely than Italian born ones to have received vaccination. This claims for better strategies to recover to vaccination migrants coming from settings with poor vaccine access. $\left[{ }^{51}\right]$ Consistently with other investigation, $\left[{ }^{52}\right]$ education is a strong predictor of higher level of vaccination and lower risk of HBV infection. Use of poppers was associated with a higher risk of infection. This observation is potentially due to the high-risk behaviours that may be induced by poppers use.[26,27] Finally, we found a direct association between familiarity with PREP and probability of being vaccinated, suggesting that participants who were familiar with PREP may be more likely to undergo vaccination if needed. 
Only nine $(0.82 \%)$ participants had a positive serology for HCV. Due to this very low number, we did not carry out formal statistical analysis. A recent meta-analysis carried out by the ECDC suggested that, although Italy is among the countries with highest prevalence of HCV infection in Europe, the prevalence of HCV among MSM is very low. [ ${ }^{53}$ ] Overall, our study suggested that MSM in Lazio did not represent a special group at risk for HCV. Moreover, all HCV positive participants were aware of their sero-status and referred for care suggesting an optimal performance of the local system for HCV diagnosis and care. $\left[{ }^{54}\right]$

One limitation of this study is the observational design and the sampling framework based on voluntary participation to the vaccine campaign, which might have biased our population sample. Indeed, we could have selected MSM at the highest risk of STI or with a highest perceived risk for viral hepatitis that did not represent the whole MSM community of Lazio. However, from a public health point of view this bias have little effect on conclusions and recommendations that claim for more effective vaccine policies against HAV and HBV. In fact, we found low prevalence of HAV immunity (consistent with the observed periodical HAV outbreaks); age-dependent immunity against HBV (consistent with biological hypothesis of waning immunity), vaccination escape of older age cohorts (consistent with previous investigations for other special groups at risk) and a very low risk for HCV infection (consistent with ECDC estimates). Another limitation was that we could not distinguish between HAV vaccinated and HAV naturally infected subjects. Thus, our estimates on HAV sero-status serve to define needs for vaccination but cannot be interpreted as predictor of risky behaviours. Finally, analysis of HBV sero-status was carried out by a multinomial estimator that strongly depends on validity of independence of irrelevant alternatives. $\left.{ }^{55}\right]$ Violation of this assumption may affect the estimates of risk in an unpredictable manner. Nevertheless, our results were strongly consistent with biological hypothesis of waning immunity and the punctual estimates were similar to those reported in other (independent) studies suggesting that multinomial estimator may have well worked in our population sample.

\section{Conclusion}

Tailored vaccine programmes aimed at immunizing MSM are critical to improve control of HAV in our setting. Due to the low level of immunity and potential exposure to risky behaviours, MSM represent a group at high risk of experiencing periodical outbreak of HAV that may eventually spread into the wider population. The level of immunity against HBV was very variable and mainly depended on age. There is a need to define a clear strategy to recover patients who escaped mandatory vaccination and inform clinicians on the need to booster subjects with low immunity and high risk of exposure, such as MSM. Finally, MSM in Lazio do not represent a special group for HCV neither in terms of risk of infection nor in terms of potential issues for therapy access.

\section{Declarations}

\section{Ethics approval and consent to participate}


INMI Spallanzani ethical board approved the study (ethical clearance N.1 of January $24^{\text {th }}$ 2017). Patients were required to sign an informed consent.

\section{Consent to publish}

Not applicable.

\section{Availability of data and materials}

The datasets used and/or analysed during the current study are available from the corresponding author on request after publication

\section{Competing interests}

All authors declared no conflict of interest

\section{Funding}

The study was funded by Lazio Region Health Authority and Italian ministry of Health "Ricerca Corrente" INMI-Spallanzani - Authors' Contributions

\section{Authors' Contributions}

SL conceived, designed and supervised the project, was responsible for funding acquisition, took the lead in writing the manuscript, performed statistical analyses, interpreted the results and designed the figures. SM was responsible for investigation and laboratory analyses. LS was responsible for direction and planning of patients' visits. GA performed the statistical analyses, drafted and revised the manuscript, and designed the figures. AA and MM designed and developed the database and processed data. FM, FA and MF were responsible for communication with patients. $C G, A B, L L, A P$ and $P M$ supervised the project. PS, VP, EM and $\mathrm{MC}$ were in charge of overall direction and planning, contributed to the implementation of the research and to the final manuscript. AZ and GI conceived and designed the project, took the lead in writing the manuscript, performed statistical analyses and interpreted the results. GI was responsible for funding acquisition and for overall direction and planning.

\section{Acknowledgements}

The authors acknowledge all the members of the PrEV study group for the priceless support for managing patients and for analysing biological samples. 


\section{Tables}

Table 1. Main characteristics of the study sample 


\begin{tabular}{|c|c|c|c|}
\hline \multicolumn{2}{|c|}{ Demographic and behaviour variables } & $\mathrm{N}$ & $\%$ \\
\hline \multirow[t]{5}{*}{ Age in years } & $18-25$ & 185 & 16.62 \\
\hline & $26-30$ & 232 & 21.09 \\
\hline & $31-35$ & 265 & 24.09 \\
\hline & $36-40$ & 229 & 20.82 \\
\hline & $41-45$ & 189 & 17.18 \\
\hline \multirow[t]{2}{*}{ Place of birth } & Italy & 1021 & 92.82 \\
\hline & abroad & 79 & 7.18 \\
\hline \multirow[t]{2}{*}{ Place of living } & outside Rome & 176 & 16.00 \\
\hline & Rome & 924 & 84.00 \\
\hline \multirow[t]{3}{*}{ Education level } & up to secondary & 427 & 38.82 \\
\hline & university & 672 & 61.09 \\
\hline & do not answer & 1 & 0.09 \\
\hline \multirow[t]{4}{*}{ Occupation } & unemployed & 120 & 10.91 \\
\hline & student & 154 & 14.00 \\
\hline & employed & 824 & 74.91 \\
\hline & do not answer & 2 & 0.18 \\
\hline \multirow[t]{3}{*}{ Use of Cannabinoids } & never & 554 & 50.36 \\
\hline & at least once in life & 543 & 49.36 \\
\hline & do not answer & 3 & 0.27 \\
\hline \multirow[t]{3}{*}{ Use of Poppers } & never & 838 & 76.18 \\
\hline & at least once in life & 259 & 23.55 \\
\hline & do not answer & 3 & 0.27 \\
\hline \multirow[t]{3}{*}{ Use of Inhalatory drugs } & never & 940 & 85.45 \\
\hline & at least once in life & 156 & 14.18 \\
\hline & do not answer & 4 & 0.36 \\
\hline \multirow[t]{3}{*}{ Use of IV drugs } & never & 1086 & 98.73 \\
\hline & at least once in life & 11 & 1.00 \\
\hline & do not answer & 3 & 0.27 \\
\hline \multirow[t]{3}{*}{ Steady sexual partner } & no & 693 & 63.00 \\
\hline & yes & 404 & 36.73 \\
\hline & do not answer & 3 & 0.27 \\
\hline \multirow[t]{4}{*}{ No. of sexual partners in the last year } & 5 or less & 645 & 58.64 \\
\hline & 6 to 12 & 220 & 20.00 \\
\hline & 13 or more & 224 & 20.36 \\
\hline & do not answer & 11 & 1.00 \\
\hline \multirow[t]{5}{*}{ Use of condom } & never & 93 & 8.45 \\
\hline & always & 364 & 33.09 \\
\hline & always for anal sex & 510 & 46.36 \\
\hline & seldom for anal sex & 127 & 11.55 \\
\hline & do not answer & 6 & 0.55 \\
\hline \multirow[t]{4}{*}{ Familiarity with PEP } & no & 422 & 38.36 \\
\hline & yes, but never taken & 569 & 51.73 \\
\hline & yes, taken at least once in life & 108 & 9.82 \\
\hline & do not answer & 1 & 0.09 \\
\hline \multirow[t]{4}{*}{ Familiarity with PREP } & no & 420 & 38.18 \\
\hline & yes, but never taken & 663 & 60.27 \\
\hline & yes, taken at least once in life & 16 & 1.45 \\
\hline & do not answer & 1 & 0.09 \\
\hline \multirow[t]{2}{*}{ Gay bars and venues } & No in the last six months & 352 & 32.00 \\
\hline & At least once in the last six moths & 746 & 67.92 \\
\hline
\end{tabular}

Page $14 / 22$ 


\begin{tabular}{|c|c|c|c|}
\hline & do not answer & 2 & 0.18 \\
\hline \multirow[t]{3}{*}{ Ever talked with the GP about your sexual behaviours } & no & 684 & 62.18 \\
\hline & yes & 409 & 37.18 \\
\hline & do not answer & 7 & 0.64 \\
\hline \multirow[t]{3}{*}{ Self-reported diagnosis of STI in the last year } & no & 866 & 78.73 \\
\hline & yes & 233 & 21.18 \\
\hline & do not answer & 1 & 0.09 \\
\hline \multirow[t]{3}{*}{ Reported HIV status } & negative & 884 & 80.36 \\
\hline & positive & 122 & 11.09 \\
\hline & do not know & 94 & 8.55 \\
\hline
\end{tabular}

IV, intravenous; PEP, post-exposure prophylaxis; PrEP, pre-exposure prophylaxis; GP, general practitioner; STI, sexual transmitted infections.

Table 2. Multivariable logistic regression model to assess predictors of HAV sero-status

\begin{tabular}{|c|c|c|c|c|}
\hline \multirow{3}{*}{\multicolumn{2}{|c|}{ Demographic and behaviour variables }} & \multicolumn{3}{|c|}{$\begin{array}{l}\text { HAV immune subjects } \\
\text { Vs } \\
\text { HAV susceptible subjects }\end{array}$} \\
\hline & & \multirow[t]{2}{*}{ OR } & $95 \% \mathrm{Cl}$ & \multirow[t]{2}{*}{ P-value } \\
\hline & & & \begin{tabular}{l|l} 
LLB & ULB
\end{tabular} & \\
\hline \multirow[t]{5}{*}{ Age } & $18-25$ & 1.00 & base & 0.207 \\
\hline & $26-30$ & 1.54 & 0.822 .88 & \\
\hline & $31-35$ & 1.07 & $0.55 \quad 2.10$ & \\
\hline & $36-40$ & 1.17 & 0.592 .31 & \\
\hline & $41-45$ & 1.74 & $0.88 \quad 3.42$ & \\
\hline \multirow[t]{2}{*}{ Place of birth } & Italy & 1.00 & base & $<0.001$ \\
\hline & abroad & 4.29 & 2.547 .23 & \\
\hline \multirow[t]{3}{*}{ Occupation } & unemployed & 1.00 & base & 0.054 \\
\hline & student & 0.40 & 0.190 .86 & \\
\hline & employed & 0.75 & 0.451 .25 & \\
\hline \multirow[t]{2}{*}{ Cannabinoids } & never & 1.00 & Base & 0.014 \\
\hline & at least once in life & 0.64 & 0.450 .91 & \\
\hline \multirow[t]{2}{*}{ Poppers } & never & 1.00 & base & 0.019 \\
\hline & at least once in life & 1.52 & $1.02 \quad 2.28$ & \\
\hline \multirow[t]{3}{*}{ No. of sexual partners } & 5 or less & 1.00 & base & 0.015 \\
\hline & 6 to 12 & 1.78 & 1.182 .68 & \\
\hline & 13 or more & 1.48 & 0.972 .26 & \\
\hline \multirow[t]{2}{*}{ Ever talked with the GP about your sexual behaviours } & no & 1.00 & Base & 0.073 \\
\hline & yes & 1.36 & 0.971 .91 & \\
\hline \multirow[t]{3}{*}{ HIV status } & negative & 1.00 & Base & 0.001 \\
\hline & positive & 0.30 & 0.150 .62 & \\
\hline & do not know & 0.88 & 0.471 .64 & \\
\hline
\end{tabular}

Immune to HAV infection: subjects with detectable anti-HAV IgG and/or anti-HAV IgM; susceptible to HAV infection: subjects with undetectable anti-HAV IgG and anti-HAV IgM. OR, odds ratio; Cl, confidence interval; LLB, lower limit bound; ULB, upper limit bound; GP, general practitioner. 
Table 3. Multivariable multinomial logistic regression model to assess predictors of HBV sero-status.

\begin{tabular}{|c|c|c|c|c|c|c|c|c|c|c|}
\hline \multicolumn{2}{|c|}{$\begin{array}{c}\text { Demographic and } \\
\text { behaviour variables }\end{array}$} & \multicolumn{3}{|c|}{$\begin{array}{l}\text { LI-vaccinated } \\
\text { vs. } \\
\text { Naïve }\end{array}$} & \multicolumn{3}{|c|}{$\begin{array}{l}\text { HI-vaccinated } \\
\text { vs. } \\
\text { Naïve }\end{array}$} & \multicolumn{3}{|c|}{$\begin{array}{l}\text { Naturally exposed } \\
\text { vs. } \\
\text { Naïve }\end{array}$} \\
\hline & & \multirow[t]{2}{*}{ RRR } & $95 \% \mathrm{Cl}$ & \multirow{2}{*}{$\begin{array}{c}\mathrm{P}- \\
\text { value }\end{array}$} & \multirow[t]{2}{*}{ RRR } & $95 \% \mathrm{Cl}$ & \multirow{2}{*}{$\begin{array}{c}\mathrm{P}- \\
\text { value }\end{array}$} & \multirow{2}{*}{ RRR } & $95 \% \mathrm{Cl}$ & \multirow{2}{*}{$\begin{array}{c}\mathrm{P}- \\
\text { value }\end{array}$} \\
\hline & & & \begin{tabular}{|l|l|} 
LLB & ULB \\
\end{tabular} & & & \begin{tabular}{|l|l|} 
LLB & ULB \\
\end{tabular} & & & \begin{tabular}{|l|l|} 
LLB & ULB \\
\end{tabular} & \\
\hline \multirow[t]{5}{*}{ Age } & $18-25$ & 1.00 & base & $<0.001$ & 1.00 & base & $<0.001$ & 1.00 & base & 0.373 \\
\hline & $26-30$ & 0.22 & $0.09 \quad 0.53$ & & 0.58 & $0.27 \quad 1.24$ & & na & na na & \\
\hline & $31-35$ & 0.33 & 0.120 .92 & & 1.87 & $0.75 \quad 4.65$ & & 3.49 & 0.6119 .91 & \\
\hline & $36-40$ & 0.06 & $0.02 \quad 0.15$ & & 0.23 & 0.51 & & 1.60 & $0.32 \quad 7.99$ & \\
\hline & $41-45$ & 0.05 & $0.02 \quad 0.13$ & & 0.05 & 0.11 & & 2.71 & 0.5613 .08 & \\
\hline \multirow{2}{*}{$\begin{array}{c}\text { Place of } \\
\text { birth }\end{array}$} & Italy & 1.00 & base & 0.012 & 1.00 & base & $<0.000$ & 1.00 & base & 0.585 \\
\hline & abroad & 0.35 & $\begin{array}{ll}0.16 & 0.79\end{array}$ & & 0.30 & $0.16 \quad 0.57$ & & 1.30 & $0.51 \quad 3.34$ & \\
\hline \multirow[t]{2}{*}{ Education } & up to & 1.00 & base & 0.193 & 1.00 & base & 0.016 & & & 0.032 \\
\hline & university & 1.36 & 0.862 .16 & & 1.60 & 1.09 & & 0.51 & 0.28 & \\
\hline \multirow[t]{3}{*}{ Occupation } & unemployed & 1.00 & base & 0.478 & 1.00 & base & 0.723 & 1.00 & base & 0.145 \\
\hline & student & 0.72 & 0.261 .99 & & 1.11 & $0.47 \quad 2.63$ & & 0.44 & $0.07 \quad 2.81$ & \\
\hline & employed & 1.22 & $0.57 \quad 2.63$ & & 0.87 & $0.47 \quad 1.60$ & & 0.42 & 0.17 & \\
\hline \multirow{4}{*}{$\begin{array}{l}\text { Familiarity } \\
\text { with PREP }\end{array}$} & no & 1.00 & base & 0.044 & 1.00 & base & 0.094 & 1.00 & base & 0.450 \\
\hline & yes, but & 1.80 & $1.13 \quad 2.84$ & & 1.28 & $\begin{array}{ll}0.88 & 1.85\end{array}$ & & 1.10 & $0.59 \quad 2.04$ & \\
\hline & yes, taken & na & na & & 8.48 & 0.8981 .04 & & 5.15 & $0.40 \quad 66.07$ & \\
\hline & $\begin{array}{c}\text { at least } \\
\text { once in life }\end{array}$ & & & & & & & & & \\
\hline \multirow[t]{2}{*}{ Poppers } & never & 1.00 & base & 0.445 & 1.00 & base & 0.257 & 1.00 & base & $<0.001$ \\
\hline & $\begin{array}{c}\text { at least } \\
\text { once in life }\end{array}$ & 0.82 & $0.48 \quad 1.38$ & & 0.79 & $0.52 \quad 1.19$ & & 3.06 & $1.65 \quad 5.65$ & \\
\hline \multirow[t]{3}{*}{ HIV status } & negative & 1.00 & base & 0.434 & 1.00 & base & 0.776 & 1.00 & base & 0.807 \\
\hline & positive & 0.73 & 0.361 .50 & & 0.82 & $0.47 \quad 1.43$ & & 1.21 & $0.53 \quad 2.75$ & \\
\hline & do not know & 0.64 & 0.291 .45 & & 0.92 & $0.51 \quad 1.68$ & & 1.29 & $0.51 \quad 3.25$ & \\
\hline
\end{tabular}

HBV naive: subjects with undetectable anti-HBs and anti-HBc; low immunity vaccinated (LI-vaccinated): subjects with anti-HBs between 1 and $10 \mathrm{UI}$ and undetectable anti-HBc; high immunity vaccinated (HI-vaccinated): subjects with anti-HBs $>10 \mathrm{UI}$ and undetectable anti-HBc; HBV naturally infected: subjects with detectable anti-HBc. RRR, relative risk ratio; $\mathbf{C l}$, confidence interval; LLB, lower limit bound; ULB, upper limit bound; na, not available.

\section{References}

1 Lanini S, Ustianowski A, Pisapia R, Zumla A, Ippolito G. Viral Hepatitis: Etiology, Epidemiology, Transmission, Diagnostics, Treatment, and Prevention. Infect Dis Clin North Am 2019 Dec;33(4):1045-1062.

2 Progress report on HIV, viral hepatitis and sexually transmitted infections 2019. Accountability for the global health sector strategies, 2016-2021. Geneva: World Health Organization; 2019

(WHO/CDS/HIV/19.7). Licence: CC BY-NC-SA 3.0 IGO. 
3 Consolidated strategic information guidelines for viral hepatitis: planning and tracking progress towards elimination. Geneva: World Health Organization; 2018. Licence: CC BY-NC-SA 3.0 IGO.

4 Lanini S, Easterbrook PJ, Zumla A, Ippolito G. Hepatitis C: global epidemiology and strategies for control. Clin Microbiol Infect 2016 Oct;22(10):833-838.

5 Lanini S, Pisapia R, Capobianchi MR, Ippolito G. Global epidemiology of viral hepatitis and national needs for complete control. Expert Rev Anti Infect Ther 2018 Aug;16(8):625-639.

6 Lanini S, Minosse C, Vairo F, et al. A large ongoing outbreak of hepatitis A predominantly affecting young males in Lazio, Italy; August 2016 - March 2017. PLoS One 2017 Nov 10;12(11):e0185428.

7 Tosti ME, Alfonsi V, Lacorte E, et al. Acute Hepatitis B After the Implementation of Universal Vaccination in Italy: Results From 22 Years of Surveillance (1993-2014). Clin Infect Dis 2016 Jun 1;62(11):1412-8.

8 Chow EP, Tucker JD, Wong FY, et al. Disparities and risks of sexually transmissible infections among men who have sex with men in China: a meta-analysis and data synthesis. PLoS One 2014 Feb 24;9(2):e89959.

9 Inoue T, Tanaka Y. Hepatitis B virus and its sexually transmitted infection - an update. Microb Cell 2016 Sep 5;3(9):420-437.

10 Nguyen T, Delaugerre C, Valantin MA, et al. Shared HCV Transmission Networks among HIV-1 Positive and Negative Men Having Sex with Men by Ultra-Deep Sequencing. J Acquir Immune Defic Syndr 2019 May 21.

11 Guzzetta G, Minosse C, Pisapia R, Giombini E, Mammone A, Vairo F, Garbuglia AR, Scognamiglio P, Capobianchi MR, Merler S, Ippolito G, Lanini S. Household transmission and disease transmissibility of a large HAV outbreak in Lazio, Italy, 2016-2017. Epidemics. 2019;29:100351.

12 Lazio Regional authority. Programma per la prevenzione delle epatiti [in Italian]. Available at: http://www.regione.lazio.it/binary/rl_sanita/tbl_normativa/SA_DCA_U00331_20_07_2017.pdf

13 WHO position paper on hepatitis A vaccines - June 2012. Wkly Epidemiol Rec 2012 Jul 13;87(28/29):261-76.

14 WHO Hepatitis A vaccination should be part of a comprehensive plan for prevention and control of viral hepatitis. Available at:

https://www.who.int/immunization/newsroom/newsstory_hepa_vaccine_control_viral_hepatitis/en/

15 von Elm E, Altman DG, Egger M, et al. The Strengthening the Reporting of Observational Studies in Epidemiology (STROBE) statement: guidelines for reporting observational studies. Lancet 2007 Oct 20;370(9596):1453-7. 
16 European Association for the Study of the Liver. EASL 2017 Clinical Practice Guidelines on the management of hepatitis B virus infection. J Hepatol. 2017 Aug;67(2):370-398.

17 Mahmood S, Shah KU, Khan TM. Immune Persistence After Infant Hepatitis-B Vaccination: A Systematic Review and Meta-Analysis. Sci Rep. 2018 Aug 8:12550.

18 Are booster immunisations needed for lifelong hepatitis B immunity? European Consensus Group on Hepatitis B Immunity. Lancet. 2000 Feb 12;355(9203):561-5.

19 Zhang Z. Model building strategy for logistic regression: purposeful selection. Ann Transl Med 2016 Mar;4(6):111.

20 European Centre for Disease Prevention and Control. Syphilis. In: ECDC. Annual epidemiological report for 2017. Stockholm: ECDC; 2019.

21 European Centre for Disease Prevention and Control. Gonorrhoea. In: ECDC. Annual epidemiological report for 2017. Stockholm: ECDC; 2019.

22 European Monitoring Centre for Drugs and Drug Addiction - Italy 2017. Available at: http://www.emcdda.europa.eu/system/files/publications/4519/TD0616150ENN.pdf

23 Brennan J, Moore K, Sizemore L, et al. Notes from the Field: Acute Hepatitis A Virus Infection Among Previously Vaccinated Persons with HIV Infection - Tennessee, 2018. MMWR Morb Mortal Wkly Rep 2019 Apr 12;68(14):328-329.

24 Ministero della Salute Linee Guida Italiane sull'utilizzo della Terapia Antiretrovirale e la gestione diagnostico-clinica delle persone con infezione da HIV-1. Available at: http://www.salute.gov.it/imgs/C_17_pubblicazioni_2696_allegato.pdf

25 Ministero della Salute Piano Nazionale Prevenzione Vaccinale PNPV 2017-2019. Available at: http://www.salute.gov.it/imgs/C_17_pubblicazioni_2571_allegato.pdf

26 Rich AJ, Lachowsky NJ, Cui Z, et al. Event-Level Analysis of Anal Sex Roles and Sex Drug Use Among Gay and Bisexual Men in Vancouver, British Columbia, Canada. Arch Sex Behav 2016 Aug;45(6):1443-51.

27 Persson KI, Tikkanen R, Bergström J, Berglund T, Thorson A, Forsberg BC. Experimentals, bottoms, riskreducers and clubbers: exploring diverse sexual practice in an Internet-active high-risk behaviour group of men who have sex with men in Sweden. Cult Health Sex 2016;18(6):639-53.

28 Bordi L, Rozera G, Scognamiglio P, et al. Monophyletic outbreak of Hepatitis A involving HIV-infected men who have sex with men, Rome, Italy 2008-2009. J Clin Virol 2012 May;54(1):26-9.

29 Ndumbi P, Freidl GS, Williams CJ, et al. Hepatitis A outbreak disproportionately affecting men who have sex with men (MSM) in the European Union and European Economic Area, June 2016 to May 2017. Euro Surveill 2018 Aug;23(33). 
30 Mariojoules J, Castro G, Pisano MB, et al. Hepatitis A outbreak affecting men who have sex with men (MSM) in central Argentina, occurred in July 2017-April 2018, later than the European outbreak. J Clin Virol 2019 Aug;117:49-53.

31 Rivas V, Barrera A, Pino K, et al. Hepatitis A outbreak since November 2016 affecting men who have sex with men (MSM) in Chile connected to the current outbreak in MSM in Europe, situation up to October 2017. Euro Surveill 2018 Mar;23(9).

32 Tanaka S, Kishi T, Ishihara A, et al. Outbreak of hepatitis A linked to European outbreaks among men who have sex with men in Osaka, Japan, from March to July 2018. Hepatol Res 2019 Jun;49(6):705-710.

33 Rodríguez-Tajes S, Perpiñán E, Caballol B, et al. Hepatitis A outbreak in Barcelona among men who have sex with men (MSM), January-June 2017: A hospital perspective. Liver Int 2018 Apr;38(4):588-593.

34 Gozlan Y, Bar-Or I, Rakovsky A, et al. Ongoing hepatitis A among men who have sex with men (MSM) linked to outbreaks in Europe in Tel Aviv area, Israel, December 2016 - June 2017. Euro Surveill 2017 Jul 20;22(29).

35 Tosti ME, Alfonsi V, Lacorte E, et al. Acute Hepatitis B After the Implementation of Universal Vaccination in Italy: Results From 22 Years of Surveillance (1993-2014). Clin Infect Dis 2016 Jun 1;62(11):1412-8.

36 Yang S, Tian G, Cui Y, et al. Factors influencing immunologic response to hepatitis $B$ vaccine in adults. Sci Rep 2016 Jun 21;6:27251.

37 Scognamiglio P, Girardi E, Fusco M, et al. Lack of implementation of Hepatitis B Virus (HBV) vaccination policy in household contacts of HBV carriers in Italy. BMC Infect Dis 2009 Jun 7;9:86.

38 Huynh C, Minuk GY, Uhanova J, et al. Serological and molecular epidemiological outcomes after two decades of universal infant hepatitis B virus (HBV) vaccination in Nunavut, Canada. Vaccine 2017 Aug 16;35(35 Pt B):4515-4522.

39 Chang MH. Breakthrough HBV infection in vaccinated children in Taiwan:surveillance for HBV mutants. Antiviral Ther 2010;15(3 Pt B):463-9.

40 Poovorawan $\mathrm{Y}$, Chongsrisawat $\mathrm{V}$, Theamboonlers $\mathrm{A}$, et al. Evidence of protection against clinical and chronic hepatitis B infection 20 years after infant vaccination in a high endemicity region. J Viral Hepat 2011;18(5):369-75.

41 Borresen ML, Koch A, Biggar RJ, et al. Effectiveness of the targeted hepatitis B vaccination program in Greenland. Am J Publ Health 2012;102(2):277-84.

42 Zhang L, Yan BY, Li MS, et al. Preliminary analysis on the prevalence and causes of breakthrough hepatitis B virus infection among children in Shandong province, China. Zhonghua yu fang yi xue za zhi [Chin J Prevent Med] 2013;47(10):933-9. 
43 Chotard J, Inskip HM, Hall AJ, et al. The Gambia Hepatitis Intervention Study: follow-up of a cohort of children vaccinated against hepatitis B. J Infect Dis 1992;166(4):764-8.

44 Yuen MF, Lim WL, Chan AO, Wong DK, Sum SS, Lai CL. 18-year follow-up study of a prospective randomized trial of hepatitis $B$ vaccinations without booster doses in children. Clin Gastroenterol Hepatol: Off Clin Pract J Am Gastroenterol Assoc 2004;2(10):941-5.

45 Hadler SC, Francis DP, Maynard JE, et al. Long-term immunogenicity and efficacy of hepatitis B vaccine in homosexual men. N Engl J Med 1986 Jul 24;315(4):209-14.

46 Zhang L, Yan B, Lv J, et al. Antibody response to hepatitis B vaccine is independently associated with hepatitis $B$ breakthrough infection among adults: Results from a three-year follow-up study in China. Vaccine 2018 Apr 12;36(16):2207-2212.

47 Poorolajal J, Hooshmand E. Booster dose vaccination for preventing hepatitis B. Cochrane Database Syst Rev 2016 Jun 7;(6):CD008256.

48 Zhao H, Zhou YH. Revaccination against hepatitis B in late teenagers who received vaccination during infancy: Yes or no? Hum Vaccin Immunother 2018 Feb 1;14(2):456-463.

49 Wang $Y$, Chen $T$, Lu LL, et al. Adolescent booster with hepatitis $B$ virus vaccines decreases HBV infection in high-risk adults. Vaccine 2017 Feb 15;35(7):1064-1070.

50 Chen YS, Chu CH, Wang JH, Lin JS, Chang YC. Predictors of Booster Response to Hepatitis B Vaccine at 15 years of age: A Cross-Sectional School-Based Study. Pediatr Neonatol 2016 Aug;57(4):302-9.

51 European Centre for Disease Prevention and Control. Public health guidance on screening and vaccination for infectious diseases in newly arrived migrants within the EU/EEA. Stockholm: ECDC; 2018

52 Zhou K, Terrault NA. Gaps in Viral Hepatitis Awareness in the United States in a Population-based Study. Clin Gastroenterol Hepatol 2019 Jun 4. pii: S1542-3565(19)30598-1.

53 European Centre for Disease Prevention and Control. Systematic review on hepatitis B and C prevalence in the EU/EEA. Stockholm: ECDC; 2016.

54 Lanini S, Scognamiglio P, Mecozzi A, et al. Impact of new DAA therapy on real clinical practice: a multicenter region-wide cohort study. BMC Infect Dis 2018 May 16;18(1):223.

55 Benson AR, Kumar R, Tomkins A. On the Relevance of Irrelevant Alternatives. WWW 2016, April 11-15, 2016, Montréal, Québec, Canada. ACM 978-1-4503-4143-1/16/04.

\section{Figures}






Figure 1

Flow chart for sample selection.

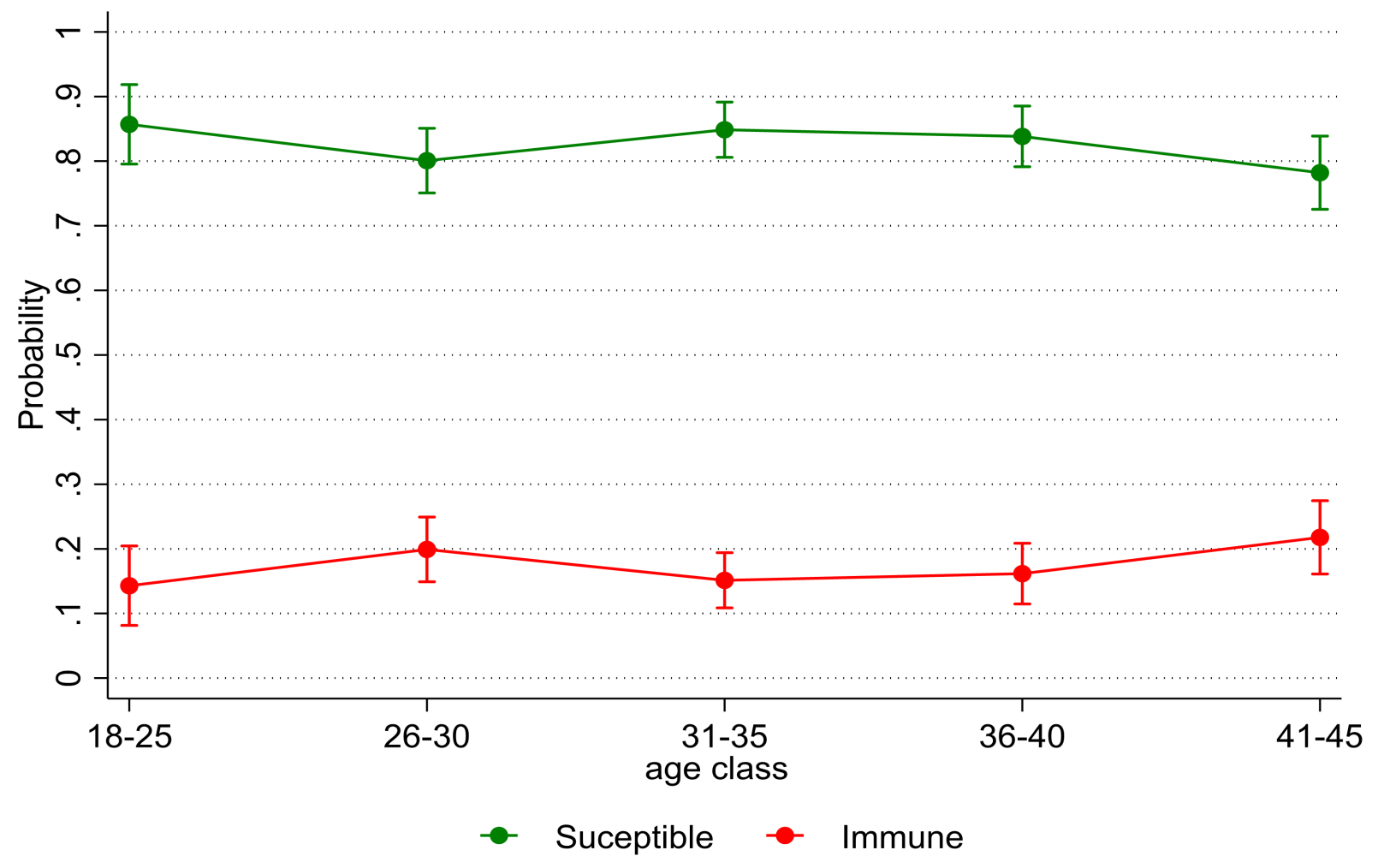

Figure 2 
Estimated effect of age on the probability to show a specific HAV sero-status. Immune: detectable anti-HAV IgG and/or anti-HAV IgM. Susceptible: undetectable anti-HAV IgG and anti-HAV IgM antibodies.

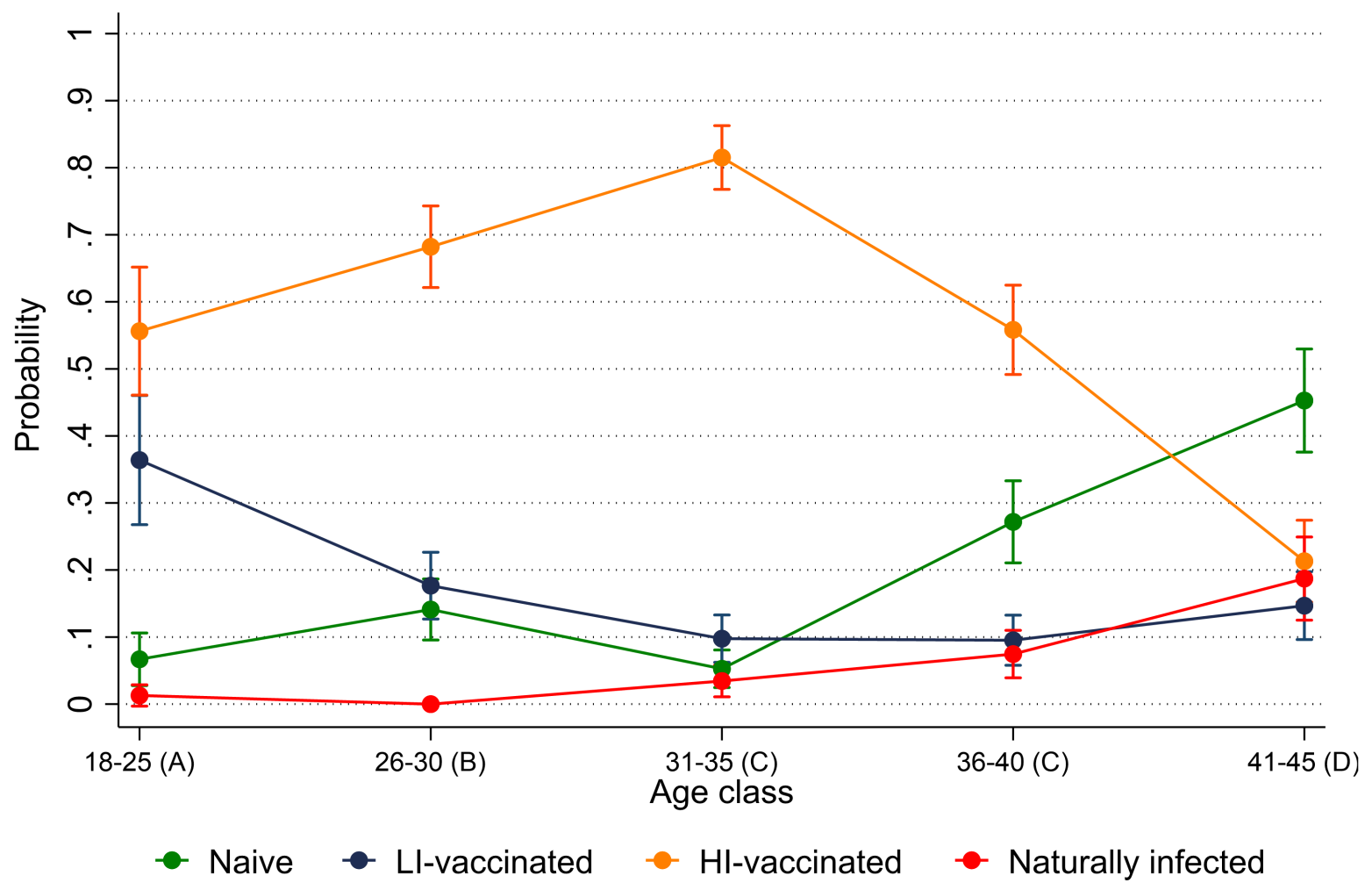

\section{Figure 3}

Estimated effect of age on the probability to show a specific HBV sero-status. (A) Age cohorts who received vaccination as infants. (B) Age cohorts who received vaccination either as infants or as 12-year children. (C) Age cohorts who received vaccination as 12-year children. (D) People born before implementation of universal vaccine programme. HBV naturally infected: detectable anti-HBcAb. HI-vaccinated: anti-HBs >10 $\mathrm{UI} / \mathrm{mL}$ and undetectable anti-HBc. LI-vaccinated: anti-HBs between 1 and $10 \mathrm{UI} / \mathrm{mL}$ and undetectable antiHBc. Naïve: undetectable anti-HBs-Ab and anti-HBc.

\section{Supplementary Files}

This is a list of supplementary files associated with this preprint. Click to download.

- Supplfile2.docx

- Supplfile3.docx

- Supplfile4.docx

- Supplentary1.pptx 